\title{
Effect of vacuum regeneration of activated carbon on volatile organic compound adsorption
}

\author{
Seo-Hyun Pak, Yong-Woo Jeon ${ }^{\dagger}$ \\ Environmental Convergence Technology Center, Korea Testing Laboratory, 87, Digital-ro 26-gil, Guro-gu, Seoul 08389, Republic of Korea
}

\begin{abstract}
Vacuum swing adsorption (VSA) is a promising treatment method for volatile organic compounds (VOCs). This study focuses on a VSA process for regenerating activated carbon spent with VOCs, and then investigates its adsorption capacities. Toluene was selected as the test VOC molecule, and the VSA regeneration experiments results were compared to the thermal swing adsorption process. Cyclic adsorption-desorption experiments were performed using a lab-scale apparatus with commercial activated carbon (Samchully Co.). The VSA regeneration was performed in air $(0.5 \mathrm{~L} / \mathrm{min})$ at $363.15 \mathrm{~K}$ and 13,332 Pa. The comparative results depicted that in terms of VSA regeneration, it was found that after the fifth regeneration, about a 90\% regeneration ratio was maintained. These experiments thus confirm that the VSA regeneration process has good recovery while operating at low temperatures $(363.15 \mathrm{~K})$ and 13,332 Pa.
\end{abstract}

Keywords: Activated carbon, Cyclic adsorption-desorption experiments, Recovery, Regeneration, Vacuum swing adsorption, Volatile organic compounds

\section{Introduction}

Volatile organic compounds (VOCs) are generated as common air pollutants emitted from chemical and petrochemical industries, including solvents such as thinners, degreasers, cleaners, lubricants, and liquid fuels. The following VOCs are the most commonly reported: formaldehyde $\left(\mathrm{CH}_{2} \mathrm{O}\right)$, tetrachloroethylene $\left(\mathrm{C}_{2} \mathrm{Cl}_{4}\right)$, benzene $\left(\mathrm{C}_{6} \mathrm{H}_{6}\right)$, toluene $\left(\mathrm{C}_{7} \mathrm{H}_{8}\right)$, xylene $\left(\mathrm{C}_{8} \mathrm{H}_{10}\right)$, and acetaldehyde $\left(\mathrm{C}_{2} \mathrm{H}_{4} \mathrm{O}\right)$. Such VOCs are hazardous to both human health and the environment, especially in their contributions to global warming; VOCs destroy the ozone stratospheric layer and a key element in photochemical smog [1-3]. Benzene and toluene are also known to cause cancer in animals; some are suspected of causing, or are known to cause, cancer and a drop in central nervous system functions in humans. In addition, the US EPA (Environmental Protection Agency) defines the effects of specific VOCs on human health (e.g. benzene, toluene) as being hazardous [4-5]. For these reasons, various technologies for VOC removal have been investigated in recent years, with treatments now including thermal oxidation, bio-filtration, absorption, adsorption, and condensation.

Technologies current being used to control VOCs can be subdivided into two major sections:
I) Decomposition: This method involves thermal oxidation and/or bio-filtration methods in order to reduce the effects of emissions by decomposing VOCs.

II) Recovery: Absorption, adsorption, and condensation are common recovery technologies.

Adsorption treatment systems using activated carbon are among the most efficient methods used for the removal and recovery of VOCs that are released into the atmosphere [3]. Ongoing studies are currently being conducted to further improve their adsorption capacities; Ryu et al. [6] recently studied the adsorption capacities of activated carbon for toluene. However, the world consumption and price of activated carbon has steadily increased, with the demand expected to further increase due to new mercury control legislation in UN member countries.

Thus, in terms of efficiency and energy requirements, it has become increasingly important to improve the regeneration processes for activated carbon [7]. Typical regeneration processes include thermal swing adsorption (TSA), which uses temperature as the manipulated variable, and pressure swing adsorption (PSA), which uses pressure as the manipulated variable.

TSA is usually applied to the removal of volatile organic components from air. For the desorption process, the bed is heated by
This is an Open Access article distributed under the terms of the Creative Commons Attribution Non-Commercial License (http://creativecommons.org/licenses/by-nc/3.0/) which permits unrestricted non-commercial use, distribution, and reproduction in any medium, provided the original work is properly cited.
Received September 30, 2016 Accepted November 28, 2016

${ }^{\dagger}$ Corresponding author

Email: ywjeon@gmail.com

Tel: +82-2-860-1682 Fax: +82-2-860-1689 
a hot gas (Air, $\mathrm{N}_{2}$, etc.). However, due to the low heat capacity of gases, a large volume of gas is needed in this process, which leads to desorption of the adsorbate diluted in the heating gas [8].

In PSA, the adsorption step is carried out at pressures higher than atmospheric. Several studies on PSA have been published, including different types of cycles and ranges of pressures [9-12]. Typically, the gas is adsorbed onto adsorbent surfaces under high pressure and is released when the pressure is reduced. The PSA process is conducted using a high pressure compressor, which leads to high power consumption and installation costs.

In vacuum swing adsorption (VSA), the adsorption step is performed under atmospheric pressure and desorption is obtained under low pressure. Chaffee et al. [13] reported the effect of vacuum pressure on the total specific power and identified an optimal vacuum pressure (40 mbar). The effects of process, feed temperature, concentration, and evacuation pressure on power consumption were studied, both via simulations and experimentation using 13X zeolite [14-15].

Advantages of the VSA process include the longer use of adsorbent, simplicity of technique, and low energy consumption. The ease of the VSA process provides greater efficiency, cost savings, and lower maintenance expenses than the PSA process [16]. In addition, the VSA process is less sensitive to sieve dusting because the pressure swings are of a lower order of magnitude; neither is the VSA process susceptible to humid conditions, whereas the PSA process needs water and oil to be eliminated. In the VSA process, the use of a vacuum step provides a greater regeneration of the molecular sieve (adsorbent), thus extending the adsorbent lifetime. Power savings created using the VSA process are as much as $50 \%$, compared to the simplest PSA system [17].

The purpose of this study is to examine the effect of VSA regeneration of spent activated carbon via a constant pressure and low temperature heating. This study focuses on the conditions for the toluene regeneration of saturated activated carbon required to achieve a 0.9 regeneration ratio. Desorption rates and the regeneration efficiency for both VSA and TSA regeneration are compared during five adsorption-regeneration cycles.

\section{Experimental}

\subsection{Adsorbent and Adsorbate}

The activated carbon from Samchully Co. (Korea) was deemed appropriate as the adsorbent in this study, for comparisons in terms of hardness, surface area, and manufacturer price of activated carbon [3]. In addition, in a pretest, the activated carbon from Samchully displayed high adsorption and desorption efficiencies for VOCs. The activated carbon (25 g) was also purchased from Samchully Co. (Korea); a $2 \mathrm{~mm}$ pellet was used. The textural properties of activated carbon were determined from $\mathrm{N}_{2}$ adsorption-desorption isotherms (ASAP 2020, Micrometrics, USA). Before the $\mathrm{N}_{2}$ adsorption-desorption analyses, the samples were degassed at $573.15 \mathrm{~K}$ for $5 \mathrm{~h}$. The $\mathrm{S}_{\text {BET }}$ of the activated carbon was 1,067 $\mathrm{m}^{2} / \mathrm{g}$. The total pore and micropore volumes were $0.58 \mathrm{~cm}^{3} / \mathrm{g}$ and $0.14 \mathrm{~cm}^{3} / \mathrm{g}$, respectively, as calculated from the Horwarth-Kawazoe and t-plot methods. The adsorbent was spent with toluene (99.99\%,
Sigma Aldrich, Korea).

\subsection{Adsorption-desorption Methods}

The adsorption-desorption cycle was conducted as schematically shown in Fig. 1. Toluene vapor was generated and controlled using a flow meter, and an air compressor. The concentration of toluene was measured using the flame ionization detector of a gas chromatograph (2010 Plus, Shimadzu, Japan). A six-way valve was installed in the gas chromatograph to analyze the concentrations of the VOC gases. An Rtx-5 column was used, and the samples were injected into the gas chromatograph every $10 \mathrm{~min}$ during the adsorption of toluene and/or benzene to obtain the breakthrough curves.

The breakthrough profile was measured by monitoring the outlet concentration as a function of time. When the outlet VOC concentration was measured for the first time, the breakthrough time was determined. The performance parameters were then calculated as follows. During adsorption, the VOCs adsorbed by the activated carbon were determined using Eq. (1).

$$
\text { VOC Removal Efficiency (R, \%) }=\frac{C^{i}-C}{C^{i}} \times 100
$$

$C^{i}$ : reactor inlet concentration of VOCs (ppm)

$C$ : reactor outlet concentration of VOCs (ppm)

Desorption experiments were conducted by controlling either the temperature or pressure. The total duration of the regeneration tests was $150 \mathrm{~min}$. Experimental desorption conditions are specified in Table 1. For all adsorption-desorption cycles, the flow rate and regeneration temperature and pressure were maintained. Thermal desorption was carried out at temperatures of 363.15 $\mathrm{K}$ and $393.15 \mathrm{~K}$. The VSA desorption was performed at 363.15 $\mathrm{K}$ and 13,332 Pa.

During the desorption experiments, the conditions were controlled at $363.15 \mathrm{~K}$ and 13,332 $\mathrm{Pa}$, and the data were recorded using a gas chromatograph (2010 Plus, Shimadzu, Japan).

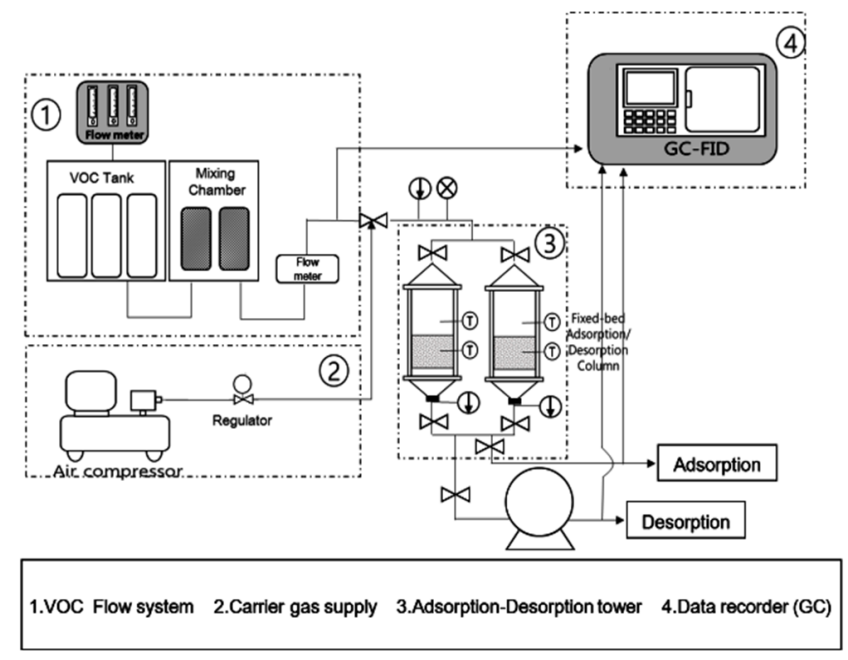

Fig. 1. Experimental apparatus for the VOC adsorption system. 
Table 1. Experimental Conditions for Desorption Tests

\begin{tabular}{c|c|c|c}
\hline Entry & $\begin{array}{c}\text { VOC, } \\
\text { Concentration }\end{array}$ & $\begin{array}{c}\text { Conditions of } \\
\text { regeneration }\end{array}$ & Cycles \\
\hline 1 & Toluene, 300 ppm & $363.15 \mathrm{~K}$ and 13,332 Pa & 5 \\
\hline 2 & Toluene, 300 ppm & $\begin{array}{c}363.15 \mathrm{~K} \text { and } \\
\text { w/o pressure }\end{array}$ & 5 \\
\hline 3 & Toluene, 300 ppm & $\begin{array}{c}393.15 \mathrm{~K} \text { and } \\
\text { w/o pressure }\end{array}$ & 5 \\
\hline
\end{tabular}

The desorption ratio Eq. (2) was measured based on the mass of toluene desorbed.

$$
D=\frac{W 1-W 2}{W 3} \times 100
$$

where $D$ is the desorption ratio of activated carbon (\%), W1 is the weight of activated carbon before desorption, $W 2$ is the weight of activated carbon after desorption, and $W 3$ is the weight of adsorbed toluene.

The method used to calculate the regeneration efficiency is described in [18].

\section{Results and Discussion}

Adsorption and VSA regeneration experiments were repeated five times in order to determine whether the VSA regeneration experiments recovered the initial adsorption capacity of the activated carbon used. The regeneration of activated carbon was carried out at a constant heating $(363.15 \mathrm{~K})$ and pressure $(13,332 \mathrm{~Pa})$, under a flow rate of $0.5 \mathrm{~L} / \mathrm{min}$. A temperature of $363.15 \mathrm{~K}$ and regeneration time of $150 \mathrm{~min}$ were typically required for the regeneration of activated carbon. The temperature was monitored by a thermocouple fixed at the surface of the activated carbon. The concentration of the exit gas from the reactor was measured with the support of a gas chromatograph with FID detector. VSA regeneration was carried out $363.15 \mathrm{~K}$ and 13,332 Pa (Entry 1) and then compared to the TSA regeneration experiments (363.15 $\mathrm{K}$ and $393.15 \mathrm{~K})$.

The ability to retain adsorption capacity of adsorbent after adsorption and desorption is one of the major point of an effective regeneration process. In Fig. 2, the adsorption breakthrough per five adsorption/VSA regeneration cycles are shown, where the breakthrough time for toluene is seen to decrease from $293 \mathrm{~min}$ to nearly $263 \mathrm{~min}$. The breakthrough time was slightly reduced in the first cycle, though it remained similar after several regeneration cycles (2-5 cycles). The adsorption breakthrough curves of the samples regenerated at $363.15 \mathrm{~K}$ and $13,332 \mathrm{~Pa}$ in the remaining samples were similar to that of fresh activated carbon. In this study, the activated carbon sample was subjected to five adsorption/desorption cycles, with no considerable loss in the adsorption capacity of the adsorbent observed, as evident in the corresponding breakthrough response.

Adsorption and desorption VSA regeneration experiments were repeated 5 times to investigate whether VSA regeneration could restore the original adsorption capacity of activated carbon. Fig. 3

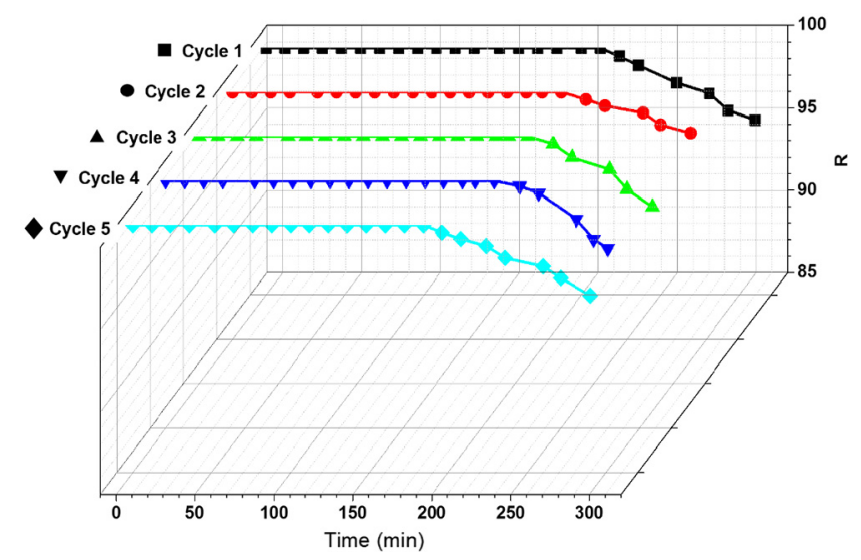

Fig. 2. Adsorption breakthrough curves of exhausted activated carbon during adsorption/VSA regeneration cycles.

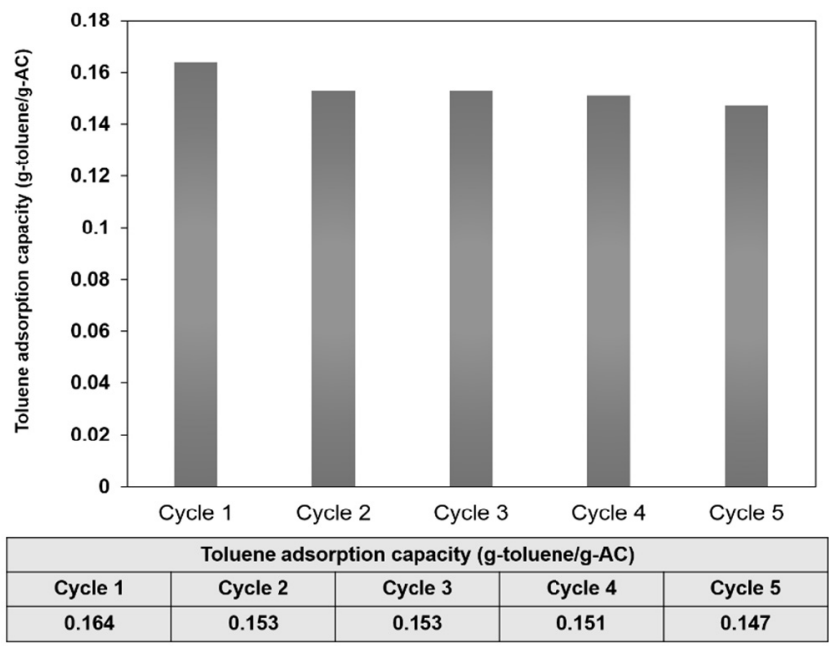

Fig. 3. Adsorption capacities ( $\mathrm{g} / \mathrm{g}$ ) of exhausted activated carbon during adsorption/VSA regeneration cycles.

shows the activated carbon adsorption capacities (g/g) for toluene, presented as a function of the number of regeneration cycles. In the figure, data points reveal that the VSA regeneration did not substantially affect the adsorption capacity of the carbon, though it restored the adsorption capacity of the activated carbon to almost its initial value; after 5 cycles, the adsorption capacity slightly decreased.

Fig. 4 presents the desorption rate of toluene for exhausted activated carbon during the adsorption/VSA regeneration cycles. After one cycle, the toluene desorption rate remained at about $80 \%$, as toluene has difficulty desorbing into the micropores of the activated carbon. Between cycles 2 to 5, the desorption rate then significantly increased until reaching a plateau. This plateau can be attributed to the desorption of the adsorbed or chemically reacted toluene in the activated carbon, as it was desorbed after every cycle during the VSA regeneration method. Compared to their original values, their results show that VSA regeneration had a remarkable effect on the breakthrough time and adsorption capacity. The VSA method implemented at a pressure of 13,332 


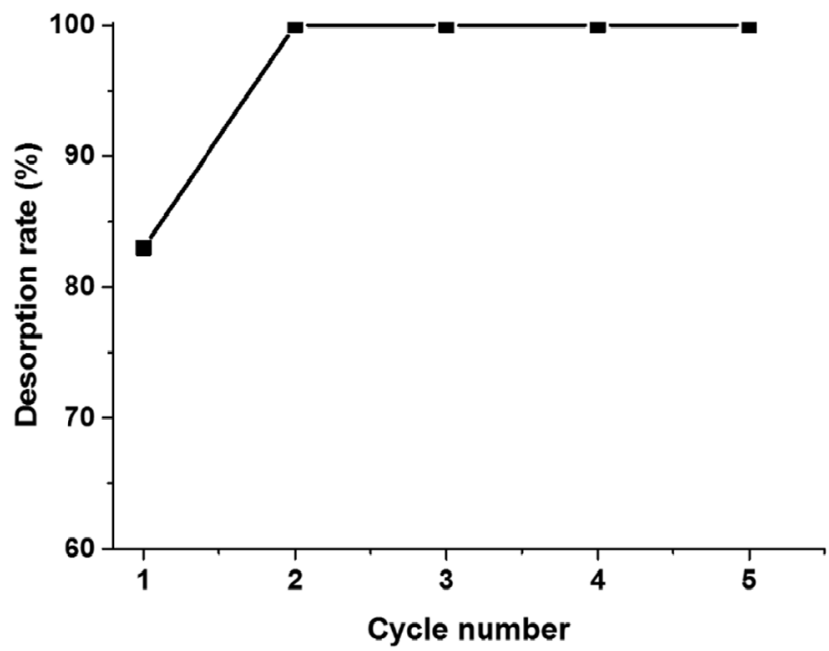

Fig. 4. Desorption rate of exhausted activated carbon during adsorption/VSA regeneration cycles.

Pa displayed both higher regeneration and energy efficiencies. And as the temperature used for the VSA regeneration process was $363.15 \mathrm{~K}$, it remained possible to effectively remove the strongly adsorbed VOC-in contrast with conventional PSA processes.

Adsorption and TSA regeneration experiments (Entry 2, Entry 3) were repeated 5 times at $363.15 \mathrm{~K}$ and $393.15 \mathrm{~K}$ without pressure, and then were compared to VSA regeneration experiments (Entry 1). As observed in the Fig. 5, the breakthrough time considerably decreases at $363.15 \mathrm{~K}$ without pressure. The breakthrough time for toluene decreased from 293 min to nearly 70 min (based on a $1 \%$ breakthrough). The regeneration performed at $363.15 \mathrm{~K}$ without pressure strongly indicates the adsorption ability of activated carbon. Generally, the shorter the breakthrough time, the lower the adsorption capacity.

The adsorption capacities (g/g) and desorption rate per five adsorption/TSA regeneration cycles (at $363.15 \mathrm{~K}$ ) are shown in Fig. 5. After the first cycle, the adsorption capacity for toluene only restored $70 \%$ of the original, and then continuously decreased during the 5 cycles. At a TSA regeneration temperature of 363.15 $\mathrm{K}$, VOCs have difficulty desorbing into the pores of the activated carbon.

Desorption rates obtained at $363.15 \mathrm{~K}$ without pressure (cycles 1-5) can be compared for Entry 1 (VSA regeneration process). The figure shows that the VSA regeneration method can more efficiently desorb toluene, and that the activated carbon is recovered at a higher rate. After the first cycle, the desorption rate for toluene is restored to almost $100 \%$ and is maintained after five cycles. This phenomenon is not observed in the TSA regeneration method $(363.15 \mathrm{~K})$; after one cycle, the desorption rate was $73 \%$, and then slightly increased from the first cycle to the second cyclereaching only about $92 \%$. In addition, the desorption rate continuously decreased during the five cycles, which can be attributed to the accumulation of toluene in the activated carbon after being desorbed every cycle.

The TSA regeneration experiments were then carried out at a temperature of $393.15 \mathrm{~K}$, which is the most commonly used temperature in TSA regeneration (Entry 3). For the desorption
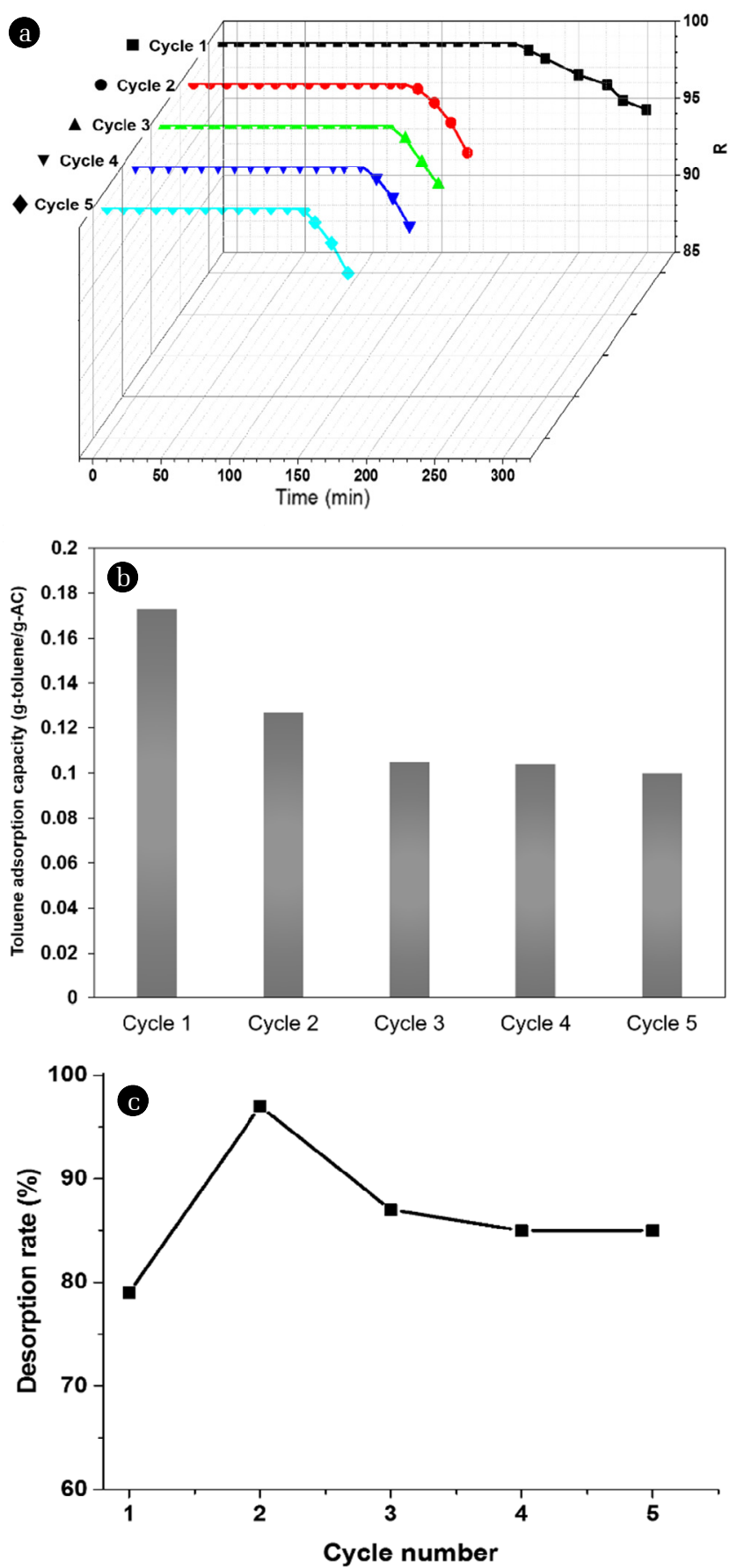

Fig. 5. a) Adsorption breakthrough curves, b) adsorption capacities (g/g), and c) desorption rates of exhausted activated carbon during adsorption/TSA regeneration cycles (363.15 K).

temperature of $393.15 \mathrm{~K}$ without pressure, the breakthrough time for toluene decreased from $293 \mathrm{~min}$ to $176 \mathrm{~min}$. This increase in the desorption temperature from $363.15 \mathrm{~K}$ to $393.15 \mathrm{~K}$ (Entries 2 and 3) significantly improved the adsorption capacities. However, after regeneration, both the adsorption capacities and desorption rates exhibited a continuous decrease; the decrease is more sig- 
nificant than that for VSA regeneration, possibly due to the partial pore blockage by VOCs. We posit that the TSA regeneration method, which is conducted at $393.15 \mathrm{~K}$, is unable to completely remove the adsorbed VOC

For the TSA regeneration process at $363.15 \mathrm{~K}$ (Fig. 7), the regeneration efficiency for toluene was $\sim 0.75$; after several regeneration
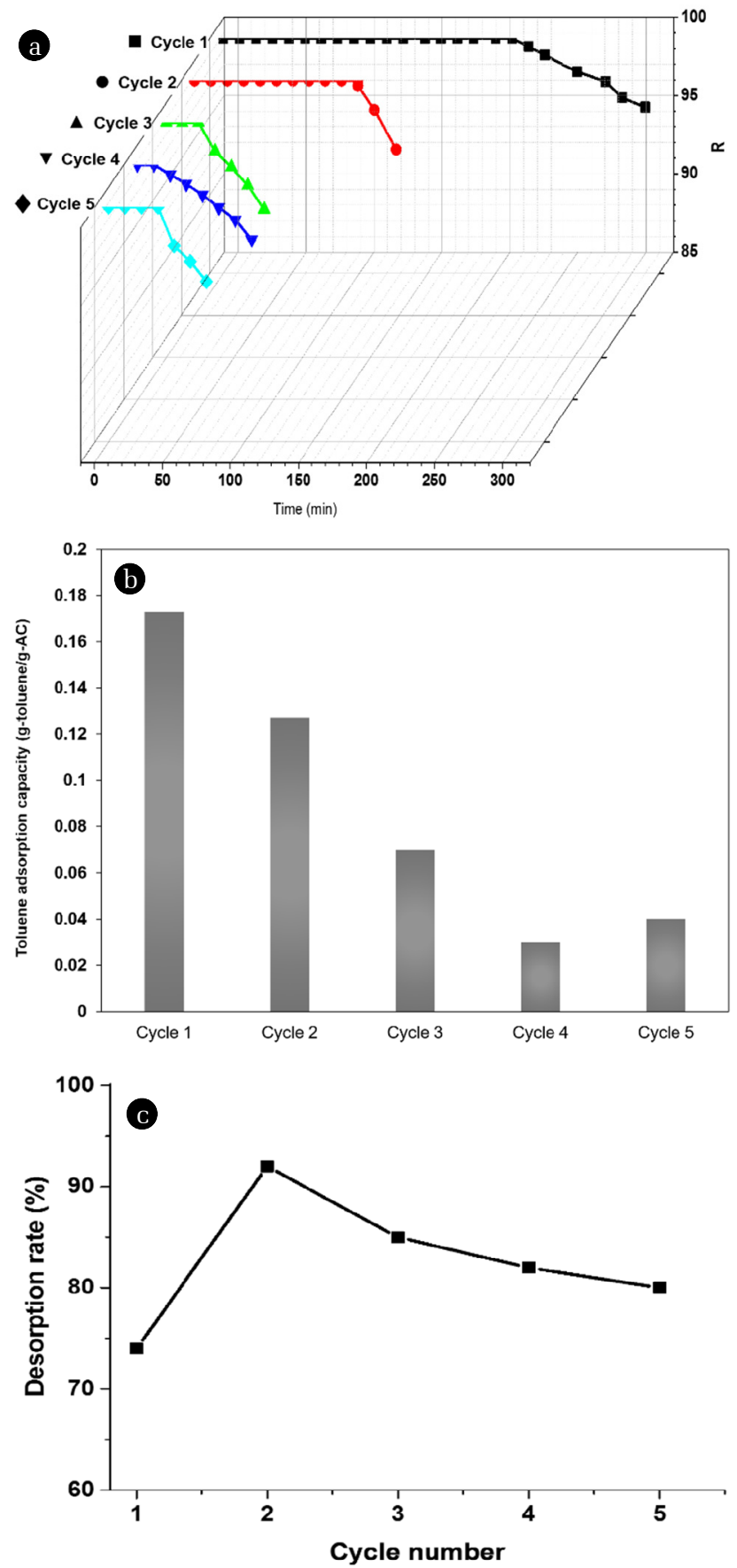

Fig. 6. a) Adsorption breakthrough curves, b) adsorption capacities (g/g), and c) desorption rates of exhausted activated carbon during adsorption/TSA regeneration cycles (393.15 K). cycles, however, the efficiency significantly decreased to 0.2 . In contrast, the regeneration efficiency for toluene was $\sim 0.78$ at $393.15 \mathrm{~K}$, and the efficiency only slightly decreased from 0.78 to $\sim 0.6$, and was maintained after five cycles.

While the VSA regeneration temperature was maintained at 363.15 $\mathrm{K}$, desorption was carried out under a constant pressure (13,332 Pa).
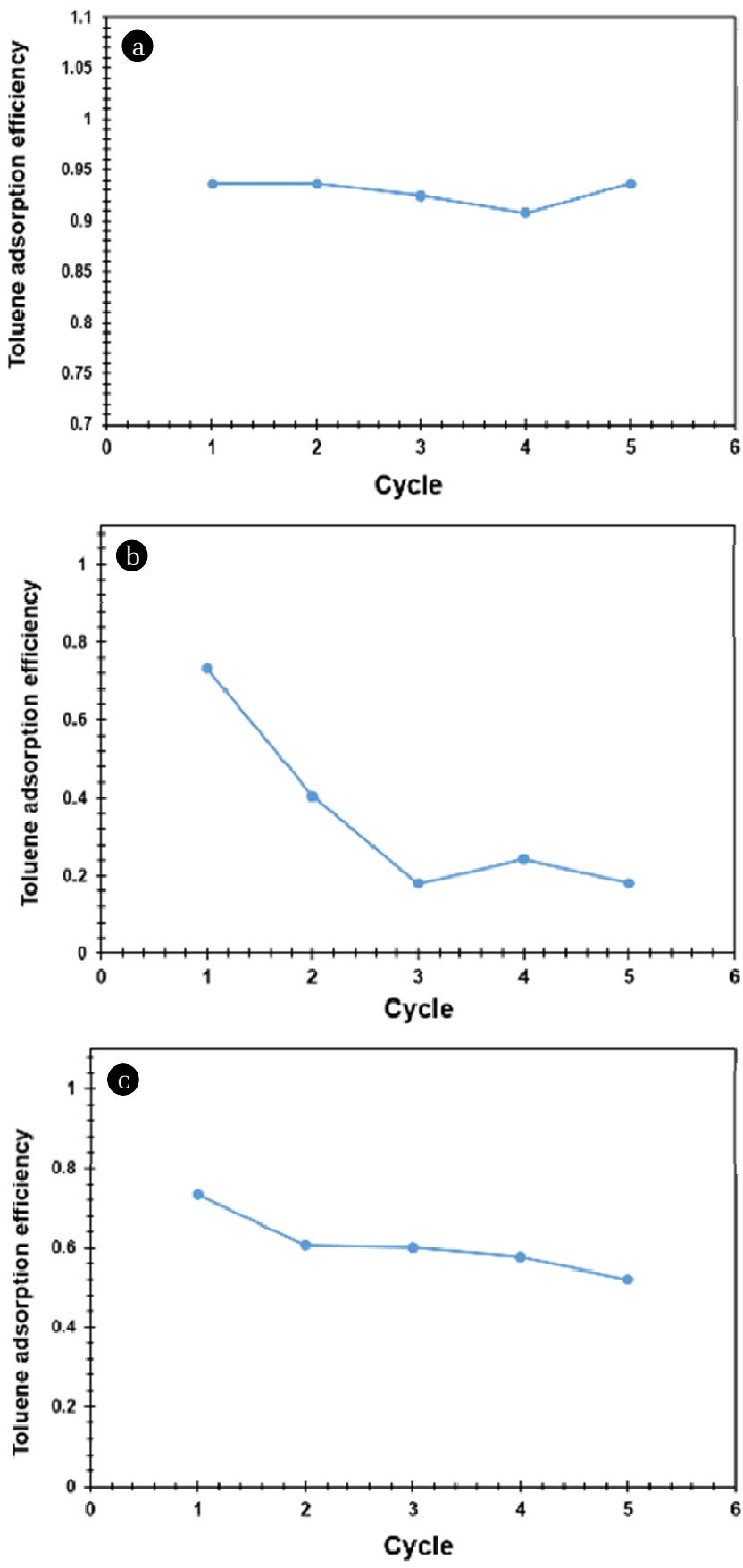

Fig. 7. Regeneration efficiencies of exhausted activated carbon for a) VSA, b) TSA (363.15 K), and c) TSA $(393.15 \mathrm{~K})$ regeneration processes. 
Under these conditions, the regeneration efficiency for toluene was 0.94 , and the spent activated carbon was then regenerated at almost equal regeneration efficiency during the five regeneration cycles.

Consequently, the VSA regeneration method was deemed effective and yielded high regeneration efficiencies compared to TSA regeneration at $363.15 \mathrm{~K}$ and $393.15 \mathrm{~K}$. This improvement can be explained by the introduction of a proper temperature (363.15 $\mathrm{K})$ at a constant pressure, which is required for successful regeneration.

\section{Conclusions}

Though the adsorption-regeneration method is an important process, it has not yet been comprehensively studied. Regeneration is considered an important process due to its advantages in process economics and energy minimization. This study investigated the VSA regeneration process of an adsorbent spent with toluene, with the aim to develop a multiple cycle regeneration system that could maintain a high regeneration efficiency. As such, the VSA regeneration process with activated carbon was subsequently compared to the TSA process.

Here, a high regeneration efficiency was achieved for toluene-spent activated carbon at $363.15 \mathrm{~K}$ and 13,332 Pa through the VSA regeneration process. Five adsorption-desorption cycles were performed, and toluene-spent activated carbon was found to be stable for multiple regenerations. VSA regeneration efficiencies greater than 0.9 were found at temperatures at $363.15 \mathrm{~K}$ under 13,332 Pa for toluene, for up to five adsorption-desorption cycles, with the adsorption capacity displaying only a slight decrease during cycles 2-5. This decrease was due to the fact that chemisorption sites were consumed on the surface and toluene was less detached in the micropores of activated carbon.

Results confirmed that over 5 cycles, low temperature (363.15 $\mathrm{K}$ ) and constant pressure (under 13,332 $\mathrm{Pa}$ ) desorption can regenerate the activated carbon adsorbed by toluene more efficiently than conventional regeneration methods.

\section{Acknowledgments}

The authors gratefully acknowledge the financial support of this work by Korea Environmental Industry \& Technology Institute (KEITI) (Project: 2014000110013).

\section{References}

1. Anfruns A, Martin MJ, Montes-Moran MA. Removal of odourous VOCs using sludge-based adsorbents. Chem. Eng. J. 2011;166:1022-1031.

2. Jung SC, Lee SH. Practical usage of low-temperature metal catalyst for the destruction of volatile organic compounds
(VOCs). J. Korean Soc. Environ. Eng. 2012;34:397-405.

3. Pak SH, Shin MS, Kim HJ, Jeon YW. Adsorption/desorption properties of activated carbon on toluene with operation condition and characteristics. J. Odor Indoor Environ. 2015;14:66-72.

4. Foster KL, Fuerman RG, Economy J, Larson SM, Rood MJ. Adsorption characteristics of trace volatile organic compounds in gas streams onto activated carbon fibers. Chem. Mater. 1992;4:1068-1073.

5. Yamamoto T, Kataoka S, Ohmori T. Characterization of carbon cryogel microspheres as adsorbents for VOC. J. Hazard. Mater. 2010;177:331-335.

6. Ryu YK, Lee HJ, Yoo HK, Lee CH. Adsorption equilibria of toluene and gasoline vapors on activated carbon. J. Chem. Eng. Data. 2002;47:1222-1225.

7. Lashaki MJ, Fayaz M, Wang HH, Hashisho Z, Philips JH, Anderson JE. Effect of adsorption and regeneration temperature on irreversible adsorption of organic vapors on beaded activated carbon. Environ. Sci. Technol. 2012;46:4083-4090.

8. Alireza D, Ali K, Abbas R, Hassan A. Regeneration of granular activated carbon saturated with gaseous toluene by microwave irradiation. Turkish J. Eng. Env. Sci. 2010;34:49-58.

9. Gomes VG, Yee KWK. Pressure swing adsorption for carbon dioxide sequestration from exhaust gases. Sep. Purif. Technol. 2002;28:161-171.

10. Ko D, Siriwardane R, Biegler LT. Optimization of a pressure-swing adsorption process using zeolite $13 \mathrm{X}$ for $\mathrm{CO}_{2}$ sequestration. Ind. Eng. Chem. Res. 2003;42:339-348.

11. Park JH, Beum HT, Kim JN, Cho SH. Numerical analysis on the power consumption of the PSA process for recovering $\mathrm{CO}_{2}$ from flue gas. Ind. Eng. Chem. Res. 2002;41:4122-4131.

12. Reynolds SP, Ebner AD, Ritter JA. New pressure swing adsorption cycles for carbon dioxide sequestration. Adsorption 2005;11:531-536.

13. Chaffee AL, Knowles GP, Liang Z, Zhang J, Xiao P, Webley PA. $\mathrm{CO}_{2}$ capture by adsorption: Material and process development. Int. J. Greenhouse Gas Control 2007;1:11-18.

14. Zhang J, Webley PA, Xiao P. Effect of process parameters on power requirements of vacuum swing adsorption technology for $\mathrm{CO}_{2}$ capture from flue gas. Energ. Convers. Manage. 2008;49:346-356.

15. Zhang J, Webley PA. Cycle development and design for $\mathrm{CO}_{2}$ capture from flue gas by vacuum swing adsorption. Environ. Sci. Technol. 2008;42:563-569.

16. Tlili N, Grévillot G, Vallières C. Carbon dioxide capture and recovery by means of TSA and/or VSA. Int. J. Greenhouse Gas Control 2009;3:519-527.

17. Yan J. Handbook of clean energy systems. Wiley; 2015. p. 1307-1336.

18. Shah IK, Pre P, Alappat BJ. Effect of thermal regeneration of spent activated carbon on volatile organic compound adsorption performances. J. Taiwan Inst. Chem. Eng. 2014;45: 1733-1738. 